\title{
A questão da democracia participativa na Venezuela durante a era Chávez: rumo a uma nova cultura política?
}

\author{
Eduardo Scheidt ${ }^{1}$
}

Resumo: no presente artigo, analisamos a questão democrática na Venezuela durante a era Chávez, desde sua primeira campanha eleitoral em 1998 até seu afastamento do poder em 2012. Utilizamos como fontes discursos e programas de governo de Chávez em que analisamos as concepções de democracia, em especial as propostas da chamada democracia participativa e protagônica. Recorremos também a uma análise de um conjunto de trabalhos acadêmicos sobre o chavismo, refletindo sobre até que ponto as transformações democráticas apontadas nos discursos e programas de governo estão ocorrendo de fato e se podemos identificar mudanças em prol de uma nova cultura política no país caribenho.

Palavras-chave: democracia; Venezuela; cultura política.

\section{The issue of participatory democracy in Venezuela during the Chavez era: towards a new political culture?}

\begin{abstract}
In this article, we analyze the question of democracy in Venezuela during the Chavez era, since his first election campaign in 1998 until the end of his government in 2012. We used as sources the Chavez speeches and government programs in which we have analyzed the concepts of democracy, in particular the proposals call participatory and protagonist democracy. We have resorted also to an analysis of several academic papers about the Chavez era, reflecting on the extent of those democratic changes outlined in speeches and government programs are taking place in fact and if we can identify changes towards a new political culture in the Caribbean country.
\end{abstract}

Key words: Democracy, Venezuela, political culture.

Artigo recebido em: 19/01/2016

Artigo aprovado para publicação em: 15/04/2016

\footnotetext{
${ }^{1}$ Professor do Departamento de Ciências Humanas e do Programa de Pós-Graduação em História Social da UERJ. Doutor em História Social pela USP. Email: edusch.uerj@gmail.com
}

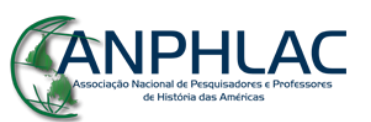

Revista Eletrônica da ANPHLAC, ISSN 1679-1061, №. 21, p. 149-175, Jul./Dez., 2016.

http://revista.anphlac.org.br 


\section{Introdução}

A questão democrática vem se sobressaindo na América Latina no contexto histórico recente, em especial a partir do processo de redemocratizações após o fim das ditaduras militares. Desde o final desses governos ditatoriais que assolaram boa parte do subcontinente, instituíram-se regimes de democracia constitucional, com eleições de representantes, liberdades de organização partidária e de expressão política e fim das práticas de terrorismo de Estado. Em geral, as mudanças se restringiram aos aspectos políticos, enquanto no que diz respeito à economia e à sociedade, deu-se continuidade ao domínio dos grandes grupos privados econômicos e as desigualdades sociais e níveis de pobreza se ampliaram, especialmente com a aplicação da agenda neoliberal em boa parte dos países latino-americanos. A crise dos recentes regimes democráticos contribuiu para o surgimento de uma série de movimentos sociais, críticos ao neoliberalismo e muitos deles reivindicando ampliações e reformulações das práticas democráticas. Ao longo dos anos 2000, foram eleitos diversos governos de esquerda e centroesquerda que implementaram importantes transformações, inclusive no que diz respeito à questão democrática. No presente momento, entretanto, boa parte da América Latina está passando por mais um período de crise concomitante com o fortalecimento da direita e processos golpistas que colocam em risco o funcionamento dos regimes democráticos.

Este artigo foca no caso venezuelano que, com a eleição de Hugo Chávez para presidência em dezembro de 1998, foi o pioneiro na opção de governos de esquerda. Ao chegar ao poder, Chávez desencadeou uma série de transformações políticas, econômicas e sociais que foram designadas como "Revolução Bolivariana" e posteriormente de "socialismo do século XXI"2. A questão democrática foi um dos eixos do programa chavista que se propôs a uma

\footnotetext{
${ }^{2}$ Ambos os termos são controversos e pouco precisos. Sobre a questão do conceito de "Revolução Bolivariana", consultar Eduardo Scheidt (2013). Neste artigo, demonstra-se que os termos "revolução", "processo revolucionário", "Revolução Bolivariana" eram recorrentes nos discursos de Chávez e eram utilizados para caracterizar o conjunto de transformações políticas e sociais iniciadas a partir de sua ascensão ao poder. O termo "Revolução Bolivariana" é um tanto impreciso e seu uso tem propósitos políticos, objetivando mobilizar e persuadir um grande número de adeptos a aderirem ao projeto chavista, dando legitimidade ideológica ao processo. Já em relação ao dito "socialismo do século XXI", ainda é algo bastante impreciso e ambíguo, mesmo em nível teórico. Impreciso porque justamente se propõe a ser "inventado" e ambíguo no sentido que admite a existência da propriedade privada na produção lado a lado com a propriedade pública e outras modalidades de "propriedade social". Pode-se até questionar até que ponto pode ser considerado "socialismo", já que não se prevê algum pleno rompimento com o sistema capitalista. Os principais aspectos do sistema seriam uma ampliação da democracia, através de diversos mecanismos de democracia direta e participativa, bem como uma distribuição social da riqueza
}

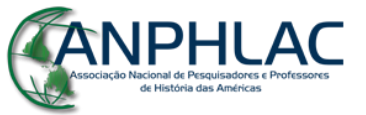

Revista Eletrônica da ANPHLAC, ISSN 1679-1061, №. 21, p. 149-175, Jul./Dez., 2016. http://revista.anphlac.org.br 
transformação do regime democrático, instituindo mecanismos de participação direta da população no processo político. Almejava-se superar a democracia representativa em prol de uma "democracia participativa e protagônica". Neste trabalho, analisamos a questão democrática na Venezuela durante a era Chávez, desde sua primeira campanha eleitoral em 1998 até seu afastamento do poder devido a problemas de saúde em 2012.

Assim como entre vários outros aspectos, no que se refere à questão democrática a análise do chavismo suscitou inúmeras polêmicas e debates acalorados na mídia, nos meios políticos e também nos estudos acadêmicos. Para alguns, Chávez ampliou o regime democrático, dando direitos de cidadania a segmentos sociais tradicionalmente excluídos e instituindo diversas formas de democracia direta. Para outros, o chavismo está associado a um rígido controle autoritário pelo Estado, significando, em última instância, a morte da democracia. Outros ainda defendem a tese de que se trata de um processo ambíguo, em que se ampliaram os direitos democráticos ao mesmo tempo em que o poder do presidente foi significativamente reforçado ${ }^{3}$.

Por que há visões tão antagônicas a respeito da democracia na Venezuela chavista? As dificuldades começam pela própria polissemia do termo democracia e da impossibilidade de uma única definição. Segundo Norberto Bobbio (2010), há inúmeros conceitos de democracia, que se alteram ao longo do tempo e entre diferentes grupos sociais em uma mesma sociedade. Na dita "sociedade ocidental", os gregos na Antiguidade são apontados como os fundadores da democracia. Naquele contexto, a democracia significava basicamente "governo do povo", entendendo-se um governo exercido diretamente pelos cidadãos que se reuniam em assembleia nas praças públicas para discutir e deliberar. Deve-se chamar a atenção para o fato de que apenas uma pequena minoria dos habitantes das cidades gregas antigas tinha direitos de cidadania, excluindo-se as mulheres, escravos e estrangeiros.

Essa identificação da democracia como um governo do povo era ainda majoritária no início do século XIX. Desta forma, a maioria dos conservadores e liberais rejeitavam a democracia, opondo-se a ela o governo exercido por representantes. Uma das argumentações

pelo Estado, especialmente com programas sociais. Para mais detalhes sobre o que caracteriza o "socialismo do século XXI" na perspectiva de seus defensores, consultar Heinz Dietrich (2005).

${ }^{3}$ Sobre as diversas caracterizações do chavismo e controvérsias em torno da questão democrática, ver Scheidt (2014 e 2015).

\section{GANPHLAC}

Revista Eletrônica da ANPHLAC, ISSN 1679-1061, №. 21, p. 149-175, Jul./Dez., 2016. http://revista.anphlac.org.br 
era de que seria impossível o povo governar de forma direta em Estados com grandes extensões territoriais. Ao longo do século XIX, entretanto, formulou-se uma concepção liberal de democracia, em que se buscou conciliar a soberania popular com a eleição de representantes. Desta forma, os cidadãos exerceriam a soberania através da escolha de representantes que governariam em seu nome. No século XX, esse modelo de democracia representativa, comumente também chamada de democracia liberal e constitucional, consolidou-se em muitos países da Europa, nos Estados Unidos e também na América Latina, exceto nos períodos de ditaduras. Bobbio, entretanto salienta que esse modelo de democracia não é unânime, sendo questionado especialmente pelas diversas vertentes do socialismo, que almejam ampliações da democracia, tanto no que diz respeito à introdução de mecanismos de participação direta dos cidadãos quanto à conquista de uma democracia social, que possibilite distribuição de renda rumo a uma maior igualdade, não se limitando na democracia política tal como almejam os liberais.

Para Ellen Wood (2011), a democracia moderna diverge radicalmente da antiga, pois enquanto essa se caracterizava por um real poder soberano de quem detinha direitos de cidadania, aquela esvazia justamente os cidadãos desse direito, limitando seu poder apenas à escolha de representantes enquanto a soberania se exerce de fato somente nos parlamentos e governos executivos. Além disso, a autora sustenta que "Na democracia capitalista moderna, a desigualdade e a exploração socioeconômicas coexistem com a liberdade e a igualdade cívicas" (WOOD, 2011, p. 173). Enquanto as liberdades e igualdades se restringem ao direito do voto, os grupos privados fazem as regras no processo econômico, permitindo as desigualdades sociais e explorações do trabalho lado ao lado com as liberdades políticas formais.

Já Carlos Nelson Coutinho (2008) aponta para as inúmeras "disputas" na definição de democracia. Para o autor, há diversas concepções do termo, conforme os contextos históricos e os diferentes grupos e classes sociais em disputa pelo poder. As concepções de democracia, pois, relacionam-se com os posicionamentos ideológicos dos grupos e agentes sociais que procuram conquistar adeptos a suas versões de democracia. Percebemos essas disputas de diferentes concepções de democracia no contexto venezuelano recente. Enquanto os chavistas denunciam as limitações da democracia representativa, que permitiam o domínio das oligarquias e do imperialismo, os opositores defendem o modelo de democracia representativa como único autenticamente democrático, acusando a proposta de democracia participativa e

\section{GANPHLAC}

Revista Eletrônica da ANPHLAC, ISSN 1679-1061, №. 21, p. 149-175, Jul./Dez., 2016. http://revista.anphlac.org.br 
protagônica de encobrir uma concentração de poderes por Chávez que manipularia politicamente os setores populares da sociedade.

As distintas concepções de democracia estão relacionadas tanto a diferentes conceitos do termo como também a práticas diferenciadas. Neste sentido, a democracia está interconectada com a questão da cultura política nas sociedades. As concepções de democracia integram, ou mais especificamente, constituem-se em elementos das culturas políticas. A noção de cultura política é complexa e de difícil definição. Fundamentamo-nos nas reflexões de Serge Berstein (1998) para quem, em linhas gerais, uma cultura política "[...] se inscreve no quadro das normas e dos valores que determinam a representação que uma sociedade faz de si mesma, do seu passado, do seu futuro.” (BERSTEIN, 1998, p. 353). A cultura política, pois, abarca além das instituições políticas vigentes numa sociedade, incluindo o conjunto de práticas e representações que uma sociedade forja em torno das questões políticas. Berstein também chama a atenção para o fato de que numa sociedade não existe uma única cultura política, mas diversas culturas políticas em disputa nos diferentes contextos históricos, mesmo que haja o predomínio de alguma determinada cultura política.

Nesse sentido, podemos dizer que boa parte dos países latino-americanos passaram por um processo de transformações em suas culturas políticas nas últimas décadas, do predomínio de culturas políticas autoritárias nos anos 60 e 70 para a passagem de culturas políticas democráticas a partir da década de 1980. Mas há diversas ideias e práticas de democracia que estão em disputa em vários países do subcontinente.

\section{A democracia participativa nos discursos e programas de governo de Hugo Chávez}

No contexto específico da Venezuela, a questão democrática se caracteriza por algumas particularidades, entre as quais o fato de o país não ter passado por regimes de ditadura militar ao longo dos anos 60 e 80. Desde 1947 até 1998, vigorou na Venezuela um regime político de democracia representativa e constitucional, caracterizado por um rodízio de poder por via eleitoral entre os partidos políticos tradicionais: AD (Aliança Democrática), de caráter socialdemocrata e o Copei (Comitê de Organização Política e Eleitoral Independente), democrata-cristão. Esse regime ficou conhecido como "Punto Fijo", devido ao pacto

\section{GANPHLAC}


estabelecido entre os principais partidos naquela cidade em 1958, consolidado posteriormente com a constituição de 1961. Nas décadas de 1960 e 1970, a situação da Venezuela contrastava com a maior parte da América Latina não apenas pelo funcionamento de uma democracia aparentemente sólida, mas também pela situação econômica favorável, especialmente pela alta do preço do petróleo, que possibilitou que as tensões sociais não fossem tão acentuadas como em outros países do subcontinente. Nos anos 1980 e 1990, entretanto, os governos daqueles partidos conduziram a Venezuela a crises econômicas profundas, demarcadas por recessões, crescimento da dívida externa, desemprego, corrupção e vertiginoso aumento da pobreza. Esta situação levou a uma sistemática descrença da população naqueles partidos e na própria democracia liberal, sendo a rebelião popular de Caracas em $1989^{4}$ um indício deste descontentamento e iminente colapso do regime de Punto Fijo. Foi nesta conjuntura que Chávez tentou chegar ao poder pela primeira vez em 1992, liderando um golpe militar frustrado. Apesar da tentativa golpista, o discurso dos conspiradores, de tom nacionalista, contra a corrupção e a política dos EUA, seduziu setores significativos da sociedade venezuelana, principalmente os mais pobres. Após ser anistiado, Chávez optou pelo caminho democrático e constitucional lançando-se candidato a presidência em 1998. A 6 de dezembro daquele ano, Chávez consagrou-se nas urnas (com 56,2\% dos votos), tomando posse como presidente em 2 de fevereiro de 1999, iniciando a partir de então uma nova etapa na história venezuelana.

O Programa de Governo de Chávez para as eleições de 1998, intitulado La propuesta de Hugo Chávez para transformar a Venezuela. Una revolución democrática, já apontava para a necessidade de uma transformação radical do país. Seu ponto de vista era o de que o regime de democracia representativa estava esgotado devido à profunda crise econômica, social e política das últimas décadas. Para Chávez, esta situação foi fruto do domínio das oligarquias e do imperialismo, possibilitada pelo regime de democracia formal que excluía a grande maioria da população de uma participação mais direta no processo político. Neste sentido, a questão da democracia teria uma importância fundamental na transformação proposta por Chávez. Seu

\footnotetext{
${ }^{4}$ Nos dias 27 e 28 de fevereiro daquele ano, houve um expressivo levante popular na cidade de Caracas contra a situação de profunda crise econômica e social, que ficou conhecido como Caracazo. O levante foi desencadeado pela revolta popular contra o então presidente recentemente empossado, Carlos Andrés Péres, que havia prometido na campanha eleitoral promover o "Estado de bem estar social" inspirado na socialdemocracia europeia, mas que decretou um pacote de medidas de caráter neoliberal ao chegar ao governo. A rebelião popular foi severamente reprimida, ocasionando a morte de centenas de manifestantes. $C f$. Karl Schurster e Rafael Araujo (2015, p. 15-16).
}

\section{GANPHLAC}

Revista Eletrônica da ANPHLAC, ISSN 1679-1061, №. 21, p. 149-175, Jul./Dez., 2016. http://revista.anphlac.org.br 
programa de governo já apontava para uma "revolução democrática", cujo primeiro passo seria a convocação de uma assembleia nacional constituinte para redigir uma nova constituição e transformar radicalmente o regime político:

\begin{abstract}
Cuando una situación llega a tal grado de descomposición, nace entonces del propio seno del pueblo una fuerza legítima indetenible, capaz de impulsar la transformación de ese marco institucional. Esa fuerza es el Poder Constituyente. Poder éste que se ha activado en Venezuela, generando un proceso transformador verdaderamente democrático y revolucionario: el Proceso Constituyente, el cual se desarrolla en varias fases, siendo algunas de ellas la convocatoria y la realización de la Asamblea Nacional Constituyente, instancia político-jurídica que originará un nuevo marco institucional para la refundación de la República, la reestructuración del Estado y el establecimiento de un nuevo consenso político y social. (CHÁVEZ, 1998, s/p)
\end{abstract}

Chamamos a atenção para o fato de que a convocação de uma assembleia constituinte foi amplamente propagada durante a campanha eleitoral de Chávez com o intuito de dar uma legitimidade popular ao processo constituinte que seria instaurado no início do seu governo. Desta forma, Chávez já procurava se contrapor a eventuais acusações de "golpe" contra a constituição em vigor com o argumento de que uma nova constituição estaria assegurada pela vontade popular.

Ainda em relação ao programa de governo de 1998, é importante salientar que já se afirmava em transformar a democracia, instituindo-se mecanismos de participação direta da população:

\begin{abstract}
Será entonces cuando el Proceso Constituyente entre en su quinta fase (ejecutiva) para sentar las bases de una nueva República que enfrente con firmeza el reto del futuro e inicie la reconstrucción de un país democrático, soberano, pacífico y próspero. Pasar de la Democracia Gobernada a la Democracia Gobernante comprende un nuevo contrato social que promueva la participación de la Sociedad Civil a través de formas de democracia directa, como la iniciativa popular y el sistema del referéndum [grifos nossos], de manera que se logre un equilibrio dinámico y estable entre el Nuevo Poder Constituido y, la vigencia permanente del Poder Constituyente. (CHÁVEZ, 1998, s/p)
\end{abstract}

Embora ainda não especificasse como concretamente funcionaria, o programa de governo chavista colocava a democracia direta como um dos eixos de sua proposta de transformação da sociedade venezuelana.

\title{
GANPHLAC
}

Revista Eletrônica da ANPHLAC, ISSN 1679-1061, №. 21, p. 149-175, Jul./Dez., 2016.

http://revista.anphlac.org.br 
Estas propostas de Chávez foram ratificadas em seu discurso de posse como presidente em 2 de fevereiro de 1999, conforme o trecho abaixo:

\begin{abstract}
Terminando el siglo XX y comenzando el siglo XXI venezolano aquí se desató una verdadera revolución, señores y yo tengo la certeza de que nosotros le vamos a dar cauce pacífico, que nosotros le vamos a dar cauce democrático a esa revolución que anda desatada por todas partes. Por tanto, dentro de esa propuesta política que es, ustedes lo saben, el eje central de ese proyecto en lo político, pero que tiene fuerte impacto en lo económico y en lo social y en lo moral y en lo jurídico y en el todo. [...]. Yo a veces no me explico cómo y tampoco voy a buscar explicaciones, personas que hace apenas un mes se referían a la Asamblea Constituyente como el caos, una obra maléfica de Satanás que nació en Barinas de nuevo y anda por Venezuela oloroso a azufre; un plan preconcebido por el tirano Chávez para establecer una dictadura en Venezuela, para acabar con la democracia; un plan maléfico. Ahora, hoy veo con alegría que dicen que «venga la Constituyente», «me lanzo a la Constituyente» han dicho algunos aquí en este Congreso. (CHÁVEZ, 1999, s/p.)
\end{abstract}

A partir de então passou a ser frequente o uso do termo "Revolução Bolivariana" para designar o processo de transformações, a ser iniciado pela assembleia constituinte. Procuravase dar um caráter pacífico e democrático ao processo, fundamentado na vontade da ampla maioria da população. Com estes argumentos, Chávez procurava refutar a ideia de que uma constituinte seria um golpe contra a constituição de 1961. Esta estaria esgotada há vários anos e a legitima vontade popular seria a elaboração de uma nova constituição.

Colocando em prática esses propósitos, uma das primeiras medidas do governo de Chávez foi convocar a eleição de uma assembleia constituinte que ainda contou com aprovação por referendo, obtendo-se $88 \%$ dos votos dos venezuelanos que compareceram às urnas. $\mathrm{O}$ chavismo conquistou uma ampla vitória, obtendo 119 das 131 cadeiras da Assembleia Constituinte. A constituinte foi imediatamente instalada e seus trabalhos duraram cerca de seis meses. O texto constitucional elaborado passou ainda por um novo referendo, realizado em 20 de dezembro de 1999, que obteve aprovação de $71 \%$ dos eleitores que compareceram à votação (WILLIAMSON, 2012, p. 610). Salientamos que o voto na Venezuela não é obrigatório e neste referendo um pouco mais de $50 \%$ dos eleitores não compareceram, fruto em boa medida do boicote chamado pela oposição que insistia em caracterizar a constituinte como um golpe contra o regime do Punto Fijo. Naquele momento, Chávez já suscitava forte oposição interna e externa. Internamente, sofria ataques dos partidos tradicionais, dos grandes empresários, dos setores

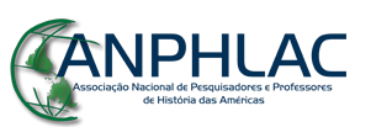

Revista Eletrônica da ANPHLAC, ISSN 1679-1061, N. 21, p. 149-175, Jul./Dez., 2016. http://revista.anphlac.org.br 
privados de comunicação e da Igreja. Do exterior, a oposição mais forte vinha do governo norteamericano. Em contrapartida, Chávez obtinha amplo apoio dos trabalhadores e das camadas mais pobres da população.

A constituição aprovada e promulgada em 1999 é indiscutivelmente uma das mais democráticas do mundo. Nas primeiras linhas de seu preâmbulo está escrita a frase: “[...] con el fin supremo de refundar la República, para estabelecer una sociedad democrática, participativa y protagónica, [...] (CONSTITUCIÓN DE LA REPÚBLICA BOLIVARIANA DE VENEZUELA, 1999, p. 1). O texto constitucional, pois, buscou institucionalizar a questão da democracia participativa e protagônica tão amplamente propagada pelos discursos de Chávez durante a campanha presidencial e após sua posse como presidente.

Sem romper com a democracia representativa, uma vez que a nova constituição continuava estabelecendo a eleição de representantes para os poderes executivos e legislativos em todos os níveis, o texto estabeleceu diversos mecanismos de democracia participativa em que instituía uma participação mais direta dos cidadãos no processo político e institucional do país. Esta questão está inserida em diversos artigos da constituição, como no de número 70:

\begin{abstract}
Artículo 70. Son medios de participación y protagonismo del pueblo en ejercicio de su soberanía en política, la elección de cargos públicos, el referendo, la consulta popular, la revocatoria del mandato, la iniciativa legislativa, constitucional y constituyente, el cabildo abierto y la asamblea de ciudadanos y ciudadanas, cuyas decisiones serán de carácter vinculante entre otros; y en lo social y económico, las instancias de atención ciudadana, la autogestión, la cogestión, las cooperativas en todas sus formas incluyendo las de carácter financiero, las cajas de ahorro, la empresa comunitaria y demás formas asociativas guiadas por valores de mutua cooperación y la solidaridad. (CONSTITUCIÓN DE LA REPÚBLICA BOLIVARIANA DE VENEZUELA, 1999, p. 11)
\end{abstract}

Uma das novidades do texto constitucional, inédita nas democracias constitucionais contemporâneas, é a revogabilidade de mandatos nos cargos eletivos, ou seja, a possibilidade de a população cassar o mandato dos eleitos por via de um referendo revogatório a partir da metade do mandato. Especificamente sobre a democracia direta, o texto anuncia inúmeras instâncias, como assembleias de cidadãos, os chamados cabildos abiertos e as diversas iniciativas legislativas. Além de questões políticas, a constituição estabelece também participação direta em questões econômicas e sociais como cooperativas, empresas comunitárias e a cogestão. Todas estas questões dependeriam ainda de leis complementares.

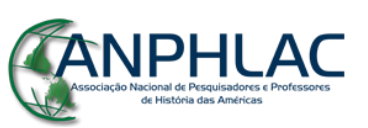

Revista Eletrônica da ANPHLAC, ISSN 1679-1061, №. 21, p. 149-175, Jul./Dez., 2016. http://revista.anphlac.org.br 
Em todo caso, o texto constitucional incentiva a população venezuelana a transformar as práticas da política do país, buscando construir uma nova cultura política no país, participativa e protagônica.

No ano seguinte à promulgação do novo texto constitucional foram convocadas novas eleições para todos os cargos eletivos. Chávez novamente se candidatou à presidência, vencendo as eleições de 2000 com 59,7\% dos votos (SCHURSTER; ARAUJO, 2015, p. 29), estabelecendo seu primeiro mandato de seis anos sob a nova constituição, que estabelecia também a possibilidade de uma única reeleição no ano de 2006. Para a campanha eleitoral de 2000, Chávez lançou um novo programa de governo, apresentado no Hotel Caracas Hilton em 22 de maio de 2000. O discurso de transformação democrática foi reiterado nessa nova campanha eleitoral, enfatizando-se o dito processo revolucionário, sempre vinculado à ampliação da democracia, conforme percebemos no seguinte trecho:

\footnotetext{
La búsqueda del equilibrio social se encuentra orientada no sólo a corregir las enormes diferencias que afectan a nuestra sociedad con su gran carga de exclusión e injusticia social, sino que se orienta al desarrollo pleno del ciudadano en los aspectos relacionados con el ejercicio de la democracia; es decir que la esencia de esta revolución democrática consiste en lograr, a través de la reivindicación y recuperación del espacio público, la vinculación de lo meramente político con todas las decisiones que afectan su vida en el día a día.

Por ello se hizo necesario cambiar el marco institucional, mediante una Asamblea Constituyente que dotara a la Nación y al Estado de una nueva Constitución y relegitimara los poderes del Estado, para lo cual era necesario establecer contrapesos entre los diferentes poderes tanto en el plano nacional, Poder Ejecutivo, Legislativo y Judicial como en el espacial, nivel nacional, estatal y municipal. (CHÁVEZ, 2000, $\mathrm{s} / \mathrm{p}$.)
}

A concepção democrática chavista centra-se nos mecanismos de controle dos cidadãos do processo político, em uma "democracia participativa" que se propunha a ampliar a tradicional democracia representativa. Nesse sentido, o programa de governo para o novo mandato se centrava na execução dos mecanismos de democracia participativa estabelecidos pela constituição recentemente aprovada. A nova realidade a ser construída se propõe a reverter a exclusão da maioria da população da participação política e dos benefícios econômicos e sociais. Através do controle do cidadão sobre o Estado, seria possível exercer uma plena soberania popular.

\section{GANPHLAC}

Revista Eletrônica da ANPHLAC, ISSN 1679-1061, №. 21, p. 149-175, Jul./Dez., 2016. http://revista.anphlac.org.br 
A partir de então, a polarização política na Venezuela se tornou mais acirrada. A oposição passou a promover boicotes, uma greve empresarial em 2001 e uma frustrada tentativa de golpe de Estado em 2002. Ainda em 2002, a oposição promoveu uma nova greve empresarial que atingiu especialmente a produção e circulação de petróleo e ficou conhecida como paro petrolero. Esse movimento se encerrou somente no início de 2003. No ano seguinte, os opositores conseguiram reunir assinaturas de $20 \%$ do eleitorado do país para convocar um referendo revogatório do mandato de Chávez. Com forte apoio entre os setores populares, Chávez resistiu a todas as ações da oposição, derrotando o golpe de 2012 e o paro petrolero, além de vencer em 2004 o referendo que propunha revogar seu mandato, permanecendo na presidência até 2006, quando inclusive venceu mais uma eleição presidencial e foi reeleito para outro período de seis anos. Nesta eleição, Chávez obteve sua maior vitória, conquistando 62,8\% dos votos num pleito em que houve um dos menores índices de abstenção: 25,3\% (SCHURSTER; ARAUJO, 2015, p. 29).

Justamente a partir desse ano de 2006, percebemos mudanças no discurso chavista sobre a questão democrática quando se começou a apregoar o dito "socialismo do século XXI". Num discurso intitulado Celebración del VII Aniversario del Gobierno Revolucionario Bolivariano, Chávez salientou a questão da democracia participativa como uma das principais transformações impulsionadas por seu governo. Sobre as formas do exercício da democracia popular, porém, há algumas mudanças em seu discurso:

\begin{abstract}
Quiero que nos dediquemos de manera intensa a la creación de la estructura, a la consolidación de la estructura o de un sistema de lo que bien podemos llamar autogobiernos locales, y esto es parte esencial de la democracia nueva, la democracia participativa, la Revolución, la democracia revolucionaria. (CHÁVEZ, 2006, p. 325) Eso es poder popular: organización, conocimiento, capacidad del pueblo, es decir, la palabra lo dice todo: poder, puedo levantar este vaso o no puedo levantarlo, eh! Puedo hablar o no puedo hablar, puedo no puedo hacerlo; es poder para el pueblo. (CHÁVEZ, 2006, p. 328)
\end{abstract}

Deste momento em diante, a questão de "autogovernos locais", especialmente as instituições denominadas Consejos Comunales $^{5}$ passam a ser cruciais na democracia

\footnotetext{
5 Os chamados "conselhos comunais" foram criados e incentivados pelo chavismo como um mecanismo de participação direta da população, num espaço em que a sociedade civil teria não somente possibilidade de se posicionar, mas também de formular e executar políticas públicas. Os conselhos comunais se constituem em
}

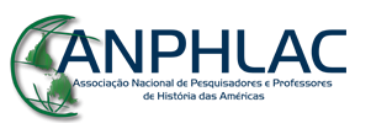

Revista Eletrônica da ANPHLAC, ISSN 1679-1061, №. 21, p. 149-175, Jul./Dez., 2016.

http://revista.anphlac.org.br 
participativa. Chávez alude à necessidade de se "aprender" o autogoverno (p. 326), convocando a população a participar dos conselhos comunais, a conviver com distintas visões e opiniões. Um novo entendimento de soberania popular é salientado nesse momento. Da clássica concepção democrático-liberal da democracia representativa, em que o único poder soberano da população é o momento da eleição de seus representantes, o discurso chavista consolida o entendimento de que a soberania popular passa pelo exercício direto do poder, através da democracia participativa.

A construção desse poder direto seria um dos mecanismos centrais da dita “transformação socialista" para a Venezuela, sempre enfatizada pelos discursos de Chávez até o final de sua vida. No programa de sua última eleição presidencial, realizada em outubro de $2012^{6}$, a democracia direta continuava sendo um dos eixos de suas propostas, conforme trecho abaixo do documento Propuesta del candidato de la Patria Comandante Hugo Chávez para la Gestión Bolivariana Socialista, 2013-2019:

\begin{abstract}
Para avanzar hacia el socialismo, necesitamos de un poder popular capaz de desarticular las tramas de opresión, explotación y dominación que subsisten en la sociedad venezolana, capaz de configurar una nueva sociabilidad desde la vida cotidiana donde la fraternidad y la solidaridad corran parejas con la emergencia permanente de nuevos modos de planificar y producir la vida material de nuestro pueblo. Esto pasa por pulverizar completamente la forma de Estado burguesa que heredamos, la que aún se reproduce a través de sus viejas y nefastas prácticas, y darle continuidad a la invención de nuevas formas de gestión política. (CHÁVEZ, 2012, p. 2)
\end{abstract}

Na ótica chavista, a Venezuela estaria numa transição ao socialismo e a conclusão desse processo passaria, entre outros aspectos, pela consolidação de reformas econômicas, políticas e sociais em benefício da maioria da população. Entre essas reformas se destacaria a ampliação da democracia, com o exercício direto do poder através dos conselhos comunais.

É evidente que os discursos de Chávez tinham propósitos ideológicos, de persuadir a população a aderir a suas propostas e, desta forma, angariar adeptos para legitimar e se

espécies de assembleias populares que funcionam de forma sistemática em diversos bairros populares e locais de trabalho na maior parte do território nacional.

${ }^{6}$ Embora a constituição de 1999 permitisse somente uma reeleição consecutiva, Chávez promoveu uma reforma constitucional aprovada por referendo popular em 2009 que permitia candidaturas a novas reeleições sucessivas sem limitações. As eleições de 2012 foram as últimas em que Chávez participou, quando já estava acometido por um câncer que o mataria em março do ano seguinte. Chávez venceu as eleições com cerca de $55 \%$ dos votos contra $44 \%$ dos votos dados a seu opositor Henrique Capriles (SCHURSTER; ARAUJO, 2015, p. 29).

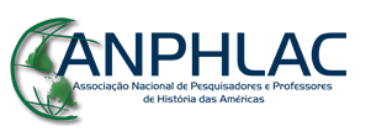

Revista Eletrônica da ANPHLAC, ISSN 1679-1061, N. 21, p. 149-175, Jul./Dez., 2016.

http://revista.anphlac.org.br 
consolidar no poder. Neste sentido, é importante em nossa leitura dos discursos chavistas recorrermos à metodologia da análise de discurso. Este método requer muitos cuidados por parte do historiador. Conforme os historiadores Ciro Flamarion Cardoso e Ronaldo Vainfas (1997), “[...] o discurso não pode ser visto como algo transparente.” (CARDOSO; VAINFAS, 1997, p. 377). Neste sentido, é fundamental, por parte do historiador, uma atitude hermenêutica, de interpretação criteriosa das fontes analisadas. Ainda conforme os autores:

Especialmente no caso de pesquisas voltadas para a história das ideias, do pensamento político, das mentalidades e da cultura, o conteúdo histórico que se pretende resgatar depende muito da forma do texto: o vocabulário, os enunciados, os tempos verbais etc. (CARDOSO; VAINFAS, 1997, p. 377)

Sendo nosso objeto a questão democrática nos discursos de Hugo Chávez, necessitaremos de uma atenção especial às formas e conteúdos de seus discursos. Entretanto, não nos restringiremos àqueles aspectos. Fundamentando-nos novamente na metodologia proposta por Cardoso e Vainfas, não podemos perder de vista que:

[...] trata-se, antes, de relacionar texto e contexto: buscar os nexos entre as ideias contidas nos discursos, as formas pelas quais elas se exprimem e o conjunto de determinações extratextuais que presidem a produção, a circulação e o consumo dos discursos. Em uma palavra, o historiador deve sempre, sem negligenciar a forma do discurso, relacioná-lo ao social. (CARDOSO; VAINFAS, 1997, p. 378)

O contexto venezuelano durante a era Chávez foi demarcado por uma profunda polarização, de disputas bastante acirradas entre os chavistas e os grupos opositores. O discurso, pois, converte-se numa importante ferramenta das lutas políticas e sociais. Para procurar se legitimar e conquistar adeptos, Chávez profere um discurso em que o país estaria passando por importantes transformações, em que a democracia participativa e protagônica estaria sendo implantada. Com esse discurso, Chávez também estaria se contrapondo a um dos eixos das críticas de seus opositores: de que concentraria poder em suas mãos e estaria construindo um regime autoritário, distanciando-se da democracia. Tomando-se os discursos dos chavistas e dos opositores, percebemos claramente que não são cópias da realidade e até mesmo parecem aludir a realidades distintas. Para uma melhor análise dos discursos e seu contexto, faz-se necessário ir além das fontes discursivas, adentrando-se em estudos acadêmicos sobre o tema.

\section{GANPHLAC}




\section{A democracia venezuelana sob a ótica dos estudos acadêmicos}

Para refletir sobre as relações entre os discursos e os contextos, questionando-nos até que ponto estas transformações vem de fato ocorrendo na Venezuela e se é possível afirmarmos que ocorre a construção de uma nova cultura política, recorremos a um conjunto de estudos acadêmicos sobre o chavismo. Mesmo entre os pesquisadores do tema, a questão é bastante controversa ${ }^{7}$. Para esta nossa análise, selecionamos um conjunto de estudos que procuram se pautar por reflexões equilibradas, demonstrando tanto avanços quanto deficiências do processo político venezuelano durante a era Chávez. Descartamos, pois, os trabalhos mais fortemente demarcados por posturas ideológicas, sejam a favor ou contra o chavismo.

Um dos trabalhos que destacamos é o livro A Revolução Venezuelana, do historiador e jornalista brasileiro Gilberto Maringoni (2009). Segundo o autor, não teriam ocorrido mudanças estruturais na sociedade venezuelana com o advento do chavismo, apesar do deslocamento das elites tradicionais do poder e as importantes reformas protagonizadas por Chávez. Sobre a

\footnotetext{
7 Cf. Scheidt (2014). O artigo demonstra que as caracterizações do chavismo são demarcadas por inúmeras polêmicas, visões distintas (e até mesmo contrapostas) não apenas na mídia e nos meios políticos, mas também entre os estudiosos acadêmicos. Especificamente, a produção acadêmica sobre o tema pode ser dividida em três grandes grupos: os contrários ao chavismo, os favoráveis ao processo e ainda os estudos que se esforçam por uma análise mais equilibrada, apontando avanços, mas também problemas no processo venezuelano. Não nos cabe aqui, no limitado espaço deste artigo, fazer uma análise aprofundada sobre os estudos do chavismo. Entretanto, consideramos importante tecer algumas considerações. No primeiro grupo, Chávez é recorrentemente caracterizado como "autoritário", "demagogo", contrário à democracia e teria conduzido o país a uma espécie de ditadura. Entre os autores deste grupo, destacamos o livro do cientista político venezuelano Enrique Neira Fernández (2006) e o historiador mexicano Enrique Krauze (2013). Os autores do segundo grupo constroem uma perspectiva justamente contrária, em que Chávez é apresentado como um "líder popular", realizador de profundas reformas em prol da população mais pobre e que teria conduzido a Venezuela a uma "democracia participativa" ou mesmo a uma transição ao socialismo. Podemos destacar neste grupo os trabalhos dos norte-americanos James Petras e Henry Veltmeyer (2009) e Gregory Wilpert (2009). Os autores do terceiro grupo, embora com divergências entre si, procuram fazer uma análise mais equilibrada apontando tanto conquistas, mas também críticas ao governo chavista. Em geral, estes autores reconhecem conquistas importantes como a redução da pobreza, a distribuição de renda, os programas sociais e os esforços de ampliar a participação democrática dos cidadãos. Mas, ao mesmo tempo, chamam a atenção para problemas como limites do processo participativo, a excessiva concentração de poder em torno da figura de Hugo Chávez e a manutenção da dependência em relação ao petróleo. Destacam-se neste grupo, a historiadora venezuelana Margarita López Maya (2008 e 2009), o sociólogo venezuelano Edgardo Lander (2005 e 2007), o cientista político colombiano Raúl Zelik (2011) e os historiadores brasileiros Gilberto Maringoni (2009), Karl Schurster e Rafael Araújo (2015). Consideramos mais pertinentes os posicionamentos dos autores desse último grupo, tanto por suas análises mais aprofundadas, demonstrando uma mais expressiva quantidade de dados e de fontes analisadas, como também por seus esforços em prol de caracterizações mais criteriosos, desvinculando-se de posicionamentos ideológicos sejam a favor ou contra Chávez e seu regime.
}

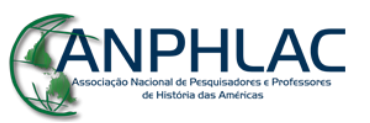

Revista Eletrônica da ANPHLAC, ISSN 1679-1061, №. 21, p. 149-175, Jul./Dez., 2016. http://revista.anphlac.org.br 
questão da ampliação da democracia, Maringoni é bastante cético ao afirmar que: "A sociedade venezuelana, anos depois da vitória de Chávez, permanece fragmentada e sem canais de participação plenamente democráticos.” (MARINGONI, 2009, p. 24). Acrescenta ainda que a Venezuela não tem tradição de participação popular na política e que os movimentos sociais e instituições como sindicatos e associações são frágeis e desprovidos de autonomia. Estes elementos estariam na base da explicação da alta centralização de poder na figura de Chávez e seu papel crucial como liderança que, na perspectiva de Maringoni, é um entrave na construção de uma sociedade autenticamente democrática ${ }^{8}$.

Já a historiadora venezuelana Margarita López Maya (2008) defende que ocorreram avanços, mas também problemáticas no processo democrático desde a chegada de Chávez ao poder. Inicialmente, a autora faz uma caracterização do chavismo como movimento, inserindoo na "nova esquerda" latino-americana, surgida em meio à crise dos paradigmas. Segundo López Maya, apesar da forte liderança da figura de Chávez, o movimento caracteriza-se como uma aliança heterogênea entre militares e civis, grupos de orientações esquerdistas tradicionais e novos. Sobre os dez anos de governo Chávez analisados no artigo, a historiadora aponta para significativas reformas políticas, econômicas e sociais, inclusive no que tange à questão democrática com a ampliação da participação popular no processo político.

Entretanto, o processo chavista se revela deficiente em diversos aspectos. Especificamente em relação à questão democrática, López Maya afirma que a participação popular foi significativamente ampliada no início do governo e garantida pela nova constituição, que introduziu diversas inovações como a aplicação de plebiscitos e referendos, a revogabilidade de mandatos e diversos mecanismos de consulta popular para planejamento e execução de políticas governamentais. Neste sentido, a constituição de 1999 foi o marco no processo de ampliação da tradicional democracia liberal, instituindo diversas formas de democracia participativa. Entretanto,

[...] la dimensión participativa tiende a restringirse para localizarse principalmente en formas de gestión popular de políticas públicas en el nivel micro, a través de los consejos comunales como privilegiadas modalidades participativas, articuladas y dependientes del gobierno central. (LÓPEZ MAYA, 2008, p. 69)

\footnotetext{
${ }^{8}$ Apesar de suas críticas, Maringoni sustenta vários aspectos positivos do processo chavista, concluindo que o país estaria passando por mudanças importantes, especialmente na elevação do padrão de vida da população em decorrência dos inúmeros programas sociais, conhecidos como misiones.
}

\section{GANPHLAC}

Revista Eletrônica da ANPHLAC, ISSN 1679-1061, №. 21, p. 149-175, Jul./Dez., 2016. http://revista.anphlac.org.br 
Sobre os conselhos comunais, que os chavistas consideram o principal mecanismo de democracia participativa desde a segunda metade do governo de Chávez, López Maya considera essa democracia direta restritiva, especialmente devido ao crescente processo de centralização e controle do executivo. Neste sentido, a autora sustenta que houve recuos nas práticas democráticas propostas nos primeiros anos do governo Chávez, que procuraram ser garantidas com a constituição de 1999. No que tange à democracia, pois, as conclusões de Margarita López Maya são de que as mudanças promovidas pelo chavismo seriam contraditórias.

Outra análise equilibrada sobre Hugo Chávez e seu regime que destacamos é a do sociólogo venezuelano Edgardo Lander (2005). O autor caracteriza o regime chavista como um projeto de reconstrução nacional resgatando o elemento popular. Trata-se, conforme o autor, fundamentalmente da ampliação da democracia representativa em direção a uma democracia participativa. Neste aspecto, Lander esboça uma interpretação diferenciada da do historiador brasileiro Gilberto Maringoni, ao reconhecer avanços na ampliação democrática. Segundo o sociólogo venezuelano,

Lo más importante que ha ocurrido en Venezuela en estos últimos cinco años no ha sido tanto la implementación de los nuevos mecanismos institucionales de la participación, sino las notorias transformaciones de la cultura política y en los procesos de inclusión, como sujetos de la acción política y organizativa de las mayorías pobres del país que se encuentran históricamente, y especialmente en las últimas dos décadas, cada vez más excluidas. (LANDER, 2005, p. 122)

Num outro artigo, Lander (2007) se debruça justamente sobre a questão democrática, em especial nos conselhos comunais. $\mathrm{O}$ autor caracteriza estes organismos como forma de a população planejar e gerir as políticas públicas. Os conselhos comunais são estimulados pelo governo não apenas para promover a participação direta da população, mas também para combater a corrupção e a burocracia, principalmente nas prefeituras e nos governos estaduais. Desta forma, os conselhos comunais promovem ligações diretas das comunidades populares com o executivo nacional, excluindo-se os poderes locais e regionais. Lander salienta o papel da participação ativa das comunidades, mas também não deixa de apontar uma crítica. Embora se constituam em espaços de participação política, na prática, unicamente os que apoiam a "revolução bolivariana" têm participado do processo, excluindo-se os grupos opositores ao

\section{GANPHLAC}

Revista Eletrônica da ANPHLAC, ISSN 1679-1061, N. 21, p. 149-175, Jul./Dez., 2016. http://revista.anphlac.org.br 
regime. Ao mesmo tempo em que há diversos mecanismos de consulta e participação direta dos que apoiam o regime, a oposição é excluída e não há diálogos com grupos opositores. O autor explica estas questões devido às fortes tensões políticas e clara polarização da Venezuela contemporânea. As oposições não são impedidas de participação política e sim se recusam a tal por serem contrárias ao regime. O governo, por outro lado, apoia-se na sua base popular e ignora a oposição.

Mesmo que reconheça o regime chavista como uma democracia popular, o autor não deixa de analisar suas vulnerabilidades, entre as quais se destaca o poder demasiadamente centralizado em Chávez. Esse excesso de personalismo é apontado como um possível obstáculo a uma plena democratização do processo político. Essa questão da centralização do poder, pois, vem sendo apontada como uma das principais deficiências da democracia venezuelana em boa parte dos trabalhos sobre o tema.

Sobre esta problemática, destacamos as reflexões de Maria Ligia Prado, Gabriela Pellegrino Soares e Sylvia Colombo (2007). Conforme as autoras, na Venezuela houve um significativo fortalecimento do poder executivo, especialmente na figura do presidente Chávez, que optou por práticas de alinhamento com os setores populares para promover as diversas reformas políticas, sociais e econômicas de cima para baixo. Neste sentido, há uma ambiguidade no processo. Por um lado, o processo venezuelano representa um considerável aumento do poder executivo, inclusive em detrimento dos demais poderes. Por outro, a aliança de Chávez com os setores populares promoveu uma crescente participação política da população e dando voz aos até então excluídos, ampliando-se a democracia que não mais se limita à tradicional democracia representativa liberal, e sim avança a uma democracia participativa.

Em uma publicação mais recente, já após o falecimento de Chávez, Karl Schurster e Rafael Araujo (2015) tecem reflexões semelhantes às de vários trabalhos analisados até aqui. Os autores também apontam para ambiguidades no processo democrático na Venezuela, conforme os trechos a seguir:

Os 14 anos de governo Hugo Chávez se fundamentaram na presença de executivo forte e centralizador. Não houve decisão política ou econômica realizada no país sem a sua anuência. [...].

\section{GANPHLAC}

Revista Eletrônica da ANPHLAC, ISSN 1679-1061, N. 21, p. 149-175, Jul./Dez., 2016.

http://revista.anphlac.org.br 
O executivo também organizou a participação popular, via misiones sociales (principal projeto social do governo com atuação nas áreas de saúde, educação, ciência e tecnologia, etc.), conselhos comunitários e apoio intenso à atuação dos chavistas nos sindicatos e entidades estudantis. Com isso, a organização popular catapultou-se vinculada ao executivo nacional, quebrando sua independência e fortalecendo o apoio ao chavismo nas batalhas políticas. (SCHURSTER; ARAUJO, 2015, p. 18)

Schurster e Araujo destacam o papel de Chávez e do poder executivo no incentivo e organização política dos cidadãos. As transformações, nesta perspectiva, são implementadas de cima para baixo. Mais do que uma aliança entre o poder executivo e os setores populares (apontadas por Prado, Soares e Colombo), os autores sustentam que o próprio poder executivo promove a organização popular para obter apoio político.

O papel de Chávez como propulsor da organização popular é também apontado na dissertação de mestrado de Mariana Bruce Baptista (2011), em que a autora fez um estudo de caso fundamentado numa ampla análise de fontes sobre o conselho comunal da Parroquia 23 de Enero, localizado num dos bairros populares mais politizados de Caracas. Neste trabalho, Mariana Bruce chama a atenção para o fato de que os conselhos comunais foram inspirados em práticas anteriores ao governo de Chávez, quando os setores populares vinham se organizando desde abajo em meio à profunda crise econômica e social nos anos 80 e 90. Naquele período, alguns governos municipais e estaduais do país, governados pela Causa-R, tinham experimentado práticas de orçamento participativo, que foram umas das aspirações de democracia direta reivindicadas pelo movimento popular que Chávez assumiu como compromisso em sua primeira campanha presidencial em 1998. Além disso, os conselhos comunais foram também inspirados em movimentos sociais de outros países latino-americanos, como os indígenas do Equador, Bolívia e em especial os neozapatistas mexicanos e sua prática do "mandar obedecendo".

Embora aponte as origens dos conselhos comunais a partir dos movimentos sociais e procure destacar seu papel no processo, Mariana Bruce, a partir da pesquisa em fontes orais, reconhece que:

Na maior parte das entrevistas com voceros comunitários, o Presidente [Chávez] é a referência fundamental, é considerado o grande incentivador de todo esse processo transformador. Tudo é feito em nome de Chávez. A grande maioria se mobilizou para o trabalho comunitário a partir das convocatórias de Chávez. O Presidente é a figura onipresente nas comunidades populares (em cartazes, nas rádios, na televisão, nas leis,

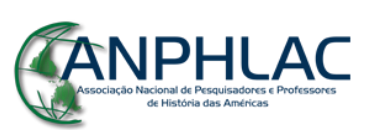


nos documentos, nas conversas en la calle, nos eventos culturais etc.). (BAPTISTA, 2011, p. 6)

Portanto, a par de todas ponderações possíveis, é evidente uma profunda dependência em relação ao Presidente que deriva do fato de se tratar de um projeto que, apesar de ser oriundo das tradições desde abajo, é incentivado e impulsionado desde arriba, tendo inclusive que se enfrentar com tentativas de controle do Estado. (BAPTISTA, 2011, p. 7)

Nesta dissertação, fica destacado o papel do movimento desde arriba, ou seja, as políticas de Estado foram fundamentais para a organização e consolidação dos conselhos comunais por toda a Venezuela. A figura de Chávez foi fundamental para impulsionar essas transformações e o projeto foi bastante dependente de suas iniciativas. Embora partes expressivas da população atendam ao chamado de se organizarem politicamente, em sua cultura política os setores populares majoritariamente identificavam em Chávez uma liderança fundamental. A autora conclui que, por um lado, houve um aumento considerável da organização popular e da participação política direta da população, mas, por outro, essa participação tem um alto grau de dependência da figura de Chávez, visto como impulsionador das transformações, e uma prática de uma democracia participativa verdadeiramente autônoma e independente é ainda um desafio a ser cumprido. Em suma, o papel do Estado é um tanto ambíguo, pois se por um lado impulsiona e organiza a participação popular, por outro, busca controla-la em prol dos interesses políticos dos ocupantes do governo, desprovendo os conselhos comunais de uma autêntica autonomia.

Outro trabalho específico sobre os conselhos comunais que merece destaque é o artigo de María Pilar García-Guadilla (2009). Num detalhado estudo sobre essas instituições, a autora aponta que por volta de 2007 havia o registro de cerca de 18.000 conselhos comunais por toda Venezuela. Os conselhos reúnem prioritariamente os setores populares e simpáticos ao governo, mas há também alguns conselhos em bairros de classe média opositores ao chavismo. Os dados apresentados por García-Guadilla comprovam o sucesso dos conselhos comunais em termos de sua abrangência, pois é claramente expressivo o grande número destas instituições em funcionamento por todo o país durante o governo de Chávez. Neste sentido, este processo parece condizer com uma das plataformas do programa chavista: a transformação da cultura política venezuelana com a construção da democracia participativa e protagônica. Entretanto, a autora argumenta que:

\section{CANPHLAC}

Revista Eletrônica da ANPHLAC, ISSN 1679-1061, Nº. 21, p. 149-175, Jul./Dez., 2016.

http://revista.anphlac.org.br 
Los objetivos y el discurso de la mayor parte de los actores gubernamentales, políticos y sociales al redor de los CC [conselhos comunais] no coinciden con las praxis. Mientras que los objetivos y el discurso presidencial hablan de empoderamiento, transformación y democratización, las praxis observadas apuntan hacia el clientelismo, la cooptación, la centralización y la exclusión por razones de polarización política. [...].

Los CC se debaten entre dos tendencias: ser cooptados o convertirse en poder popular autónomo; hasta el momento, las praxis apuntan hacia la cooptación bien sea del gobierno o del PSUV, el cual se vincula estrechamente con el gobierno. (GARCÍAGUADILLA, 2009, p. 320-321)

Neste estudo que analisamos anteriormente, o papel do Estado como controlador dos conselhos comunais é apontado com mais profundidade. Segundo García-Guadilla, estas instituições estão se convertendo mais em instâncias clientelistas manipuladas pelo Estado e menos em espações de reais práticas de democracia participativa. Embora estas sejam as práticas predominantes, a autora não deixa de destacar que no interior dos conselhos comunais, coexiste a tendência de se constituírem em autênticos poderes populares autônomos e independentes. Há, pois, lutas e tensões entre estas duas tendências no interior dos conselhos comunais.

\section{Considerações finais: Venezuela rumo a transformações na cultura política?}

Podemos concluir que a questão da democracia participativa e protagônica na Venezuela é complexa. Os discursos e programas de governo de Chávez colocavam a questão como uma das principais transformações que estariam sendo implementadas no país e os conselhos comunais eram apontados como espaços privilegiados em que a participação direta dos cidadãos estaria sendo protagonizada. A maioria dos autores que se debruçaram sobre o tema, entretanto, são bastante críticos a respeito da questão.

Entre os autores acadêmicos que selecionamos para esta análise, encontramos posições extremadas como a de Gilberto Maringoni que é cético quanto à democratização na Venezuela e acredita que todas as transformações são implementadas de cima para baixo e a de Edgardo Lander que sustenta que o chavismo promoveu uma real democratização do país, transformando a cultura política em participativa e protagônica, ainda que hajam problemáticas como a exclusão de opositores devido à alta polarização e tensões políticas. Em todo caso, a grande maioria dos autores critica o centralismo de poder na figura de Chávez e muitos afirmam que,

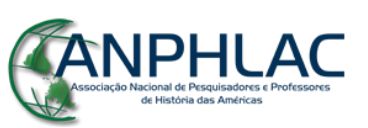

Revista Eletrônica da ANPHLAC, ISSN 1679-1061, N. 21, p. 149-175, Jul./Dez., 2016. http://revista.anphlac.org.br 
embora o chavismo tenha estimulado e mesmo promovido a organização popular, busca controlá-la com práticas clientelistas e burocráticas.

Quando falamos em cultura política, estamos tratando de questões amplas e complexas, que envolvem crenças, ideias, mas também práticas e atitudes dos agentes sociais perante a política. Nesse sentido, ao analisar transformações na cultura política, temos que também levar em conta as continuidades. A cultura política latino-americana é historicamente demarcada pelo forte personalismo e pouca autonomia dos agentes sociais e dos movimentos populares. Conforme apontamos anteriormente, os autores são praticamente unânimes em destacar o personalismo de Chávez e sua conversão no papel de líder perante seus seguidores. Desta forma, o processo de construção de uma democracia participativa no país tem a particularidade de ser impulsionado fundamentalmente de cima para baixo, a partir de incentivos do Estado e do próprio Chávez, e não um processo de baixo para cima a partir dos movimentos sociais.

Nosso posicionamento é que, a despeito do centralismo e controle do Estado sobre as organizações populares, em especial os conselhos comunais, acreditamos que o chavismo promoveu uma expressiva inclusão política e estímulos à participação da maioria da população, em especial as camadas mais pobres, que eram tradicionalmente excluídas. Neste sentido, também acreditamos que existe na Venezuela a construção de uma democracia participativa, que se coloca como alternativa ou complementar ao modelo tradicional de democracia representativa. Entretanto, é preciso reconhecer que se trata de um processo em curso, com vários defeitos e problemas, como a burocratização, as tentativas de controle dos conselhos comunais pelo governo e o partido governante, a falta de diálogo com os opositores políticos, etc. Mas, indiscutivelmente, é um processo inovador, que está transformando a cultura política do país. De cidadãos passivos que se restringiam a ter o direito ao voto, os venezuelanos se transformam em agentes mais ativos, com possibilidades de ter uma atuação mais direta no processo político do país.

Se a cultura política participativa e protagônica irá de fato se consolidar, é algo que ainda está indefinido. Desde o falecimento de Chávez, o país entrou num novo período de crise com inflação em alta, preço do petróleo em baixa, desabastecimento de produtos e acirramento da polarização política. Concomitante com a crise, o chavismo vem perdendo apoio popular. Embora mesmo após o falecimento de Chávez tenha vencido o pleito presidencial de 2013, com a eleição de Nicolás Maduro e obtido maioria nas eleições municipais em dezembro do mesmo

\section{GANPHLAC}

Revista Eletrônica da ANPHLAC, ISSN 1679-1061, №. 21, p. 149-175, Jul./Dez., 2016. http://revista.anphlac.org.br 
ano, o chavismo acabou de passar por uma grande derrota ao perder a maioria parlamentar nas eleições de dezembro de 2015.

O caso venezuelano é um exemplo de que a democracia na América Latina é uma questão em disputa. Conforme mencionamos no início do artigo, o subcontinente passou por um processo de redemocratização após as ditaduras militares, com a instituição de regimes de democracia representativa ao longo da década de 1980, que entraram em crise na década seguinte. Em meio a este processo, vários movimentos sociais reivindicaram uma ampliação da democracia em prol de mecanismos de participação direta. Na virada do milênio, alguns governos de esquerda assumiram o compromisso da construção da democracia participativa e protagônica, como o caso venezuelano aqui analisado e também os governos de Evo Morales na Bolívia e Rafael Correa no Equador.

Entretanto, este processo poderá passar por retrocessos com o atual período de crise em que se percebe um refortalecimento da direita, como na citada vitória da oposição nas últimas eleições parlamentares na Venezuela, a eleição do direitista Mauricio Macri para a presidência da Argentina, os movimentos pelo impeachment de Dilma Rousseff no Brasil e a acentuada queda de popularidade da presidente chilena Michelle Bachelet. Além disso, embora no final do século passado muitos consideravam que a democracia estaria consolidada na América Latina, percebemos a retomada de golpes de Estado nos últimos anos, como a tentativa de golpe na Venezuela em 2002, a derrubada do governo de Manuel Zelaya em 2009 em Honduras, o golpe travestido de constitucionalidade que retirou Fernando Lugo do governo paraguaio em 2012 e o processo em curso de impeachment contra Dilma em nosso país, sem a identificação de qualquer crime de responsabilidade. Mais do que uma disputa entre distintas concepções, a própria democracia latino-americana, portanto, está em risco.

\section{Fontes}

CHÁVEZ, Hugo. Celebración del VII Aniversario del Gobierno Revolucionario Bolivariano. In: La unidad latinoamericana. Bogotá: Oceán Sur, 2006, p. 307-344.

\section{CANPHLAC}


- Discurso de toma de posesión. 1999. Disponível em: <www.analitica.com/bitblio/hchavez.>, acessado em 15 jul. 2013.

Presentación del Mensaje Anual del Presidente a la Asamblea Nacional. In: El golpe fascista contra Venezuela. Havana: Ediciones Plaza, 2003, p. 161-200.

Programa de gobierno. 2000. Disponível em: <www.analitica.com/bitblio/hchavez.>, acessado em 15 jul. 2013.

La propuesta de Hugo Chávez para transformar a Venezuela Una revolución democrática. 1998. Disponível em: 〈www.analitica.com/bitblio/hchavez.>, acessado em 15 jul. 2013.

Propuesta del candidato de la Patria Comandante Hugo Chávez para la Gestión Bolivariana Socialista, 2013-2019. 2012. Disponível em <http://blog.chavez.org.ve/programapatria-venezuela-2013-2019/\#.UlwlD1Pvco4.> Acessado em 12 ago. 2013.

CONSTITUCIÓN DE LA REPÚBLCIA BOLIVARIANA DE VENEZUELA, 1999. Disponível em <http://www.ministeriopublico.gob.ve/c/document_library/get_file?p_1_id=10240\&folderId= 12935\&name=DLFE-302.pdf\&version=1.6> . Acessado em 05 jan. 2016.

\section{GANPHLAC}

Revista Eletrônica da ANPHLAC, ISSN 1679-1061, №. 21, p. 149-175, Jul./Dez., 2016. http://revista.anphlac.org.br 


\section{Bibliografia}

ANSALDI, Waldo; GIORDANO, Verónica. América Latina. La construcción del orden. Tomo II: de las sociedades de masas a las sociedades en procesos de reestructuración. Buenos Aires: Ariel, 2012.

AYALA, Mario; QUINTERO, Pablo (Org.). Diez años de revolución en Venezuela: historia, balance y perspectivas (1999-2009). Ituzaingó: Maipue, 2009.

BAPTISTA, Mariana Bruce Ganem. A "Democracia Participativa y Protagónica", o Povo e o Líder: as experiências dos Consejos Comunales na Parroquia 23 de Enero (Caracas/Venezuela). Niterói: UFF, 2011. Dissertação de mestrado.

BERSTEIN, Serge. A cultura política. In: RIOUX, Jean-Pierre; SIRINELLI, Jean-François. Para uma história cultural. Lisboa: Estampa, 1998, p. 349-363.

BOBBIO, Norberto; MATTEUCCI, Nicola; PASQUINO, Gianfranco. Dicionário de política. Brasília: Editora UnB, 2010, 2v.

BORON, Atilio. Estado, capitalismo y democracia en América Latina. Buenos Aires: Clacso, 2003.

CARDOSO, Ciro Flamarion; VAINFAS, Ronaldo. História e análise de textos. In: Domínios da História: ensaios de teoria e metodologia. Rio de Janeiro: Campus, 1997, p. 375399.

COUTINHO, Carlos Nelson. Democracia: um conceito em disputa. 2008. Disponível em www.socialismo.org.br/portal/filosofia/155-artigo/699-democracia-um-conceito-em-disputa.

Acessado em março de 2015.

DIETERICH, Heinz. Hugo Chávez y el socialismo del siglo XXI. Buenos Aires: Nuestra América, 2005.

GARCÍA-GUADILLA, María Pilar. La praxis de los Consejos Comunales ¿Poder popular o instancia clientelar? In: AYALA, Mario; QUINTERO, Pablo (Org.). Diez años de revolución en Venezuela: historia, balance y perspectivas (1999-2009). Ituzaingó: Maipue, 2009, p. $297-$ 326.

KRAUSE, Enrique. O poder e o delírio. São Paulo: Benvirá, 2013.

LANDER, Edgardo. El Estado y las tensiones de la participación popular en Venezuela. $O S A L$, ano VII, n. 22. Buenos Aires: CLACSO, 2007, p. 65-86.

\section{GANPHLAC}

Revista Eletrônica da ANPHLAC, ISSN 1679-1061, №. 21, p. 149-175, Jul./Dez., 2016.

http://revista.anphlac.org.br 
. Izquierda y populismo: alternativas al neoliberalismo en Venezuela. In: RODRÍGUEZ GARAVITO, César et. al. (Editores). La nueva izquierda en América Latina: sus orígenes y trayectoria futura. Bogotá: Grupo Editorial Norma, 2005, p. 97-146.

LÓPEZ MAYA, Margarita. Venezuela: Hugo Chávez y el bolivarianismo. Revista Venezuelana de Economía y Ciencias Sociales, vol. 14, n. 3. Caracas: Universidad Central de Venezuela, 2008, p. 55-82.

. El movimiento bolivariano: ascenso al poder y gobierno hasta 2008. In: AYALA, Mario e QUINTERO, Pablo (Orgs.). Diez años de revolución en Venezuela. Historia, balance y perspectivas (1999-2009). Ituzaingó, Argentina: Maipue, 2009, p. 97-130.

MARINGONI, Gilberto. A Revolução Venezuelana. São Paulo: UNESP, 2009.

NEIRA FERNÁNDEZ, Enrique. Venezuela: IV ${ }^{\mathrm{a}}$ y V $\mathrm{V}^{\mathrm{a}}$ Repúblicas (1958-2006). Mérida Venezuela: Talleres Gráficos Universitarios, ULA, 2006.

PETRAS, James; VELTMAYER, Henry. Espejismos de la izquierda en América Latina. México: Lumen México, 2009.

PRADO, Maria Ligia; SOARES, Gabriela Pellegrino; COLOMBO, Sylvia. Reflexões sobre a democracia na América Latina. São Paulo: Senac, 2007.

SCHEIDT, Eduardo. Caracterizações do governo de Hugo Chávez na ótica dos estudos acadêmicos. Cadernos do tempo presente. São Cristóvão, UFS, v. 16, 2014, p. 26-39.

. "Revolução Bolivariana" nos discursos de Hugo Chávez. Cordis: Revista Eletrônica de História Social da Cidade. São Paulo, PUCSP, v. 11, 2013, p. 155-193.

A Venezuela durante os governos de Hugo Chávez: ampliação da democracia ou autoritarismo de Estado? In: SCHUSTER, Karl; ARAUJO, Rafael. A era Chávez e a Venezuela no tempo presente. Rio de Janeiro: Autografia, 2015, p. 179-194.

SCHUSTER, Karl; ARAUJO, Rafael. A era Chávez e a Venezuela no tempo presente. Rio de Janeiro: Autografia, 2015.

WILLIAMSON, Edwin. História da América Latina. Lisboa: Edições 70, 2012.

WILPERT, George. La transformación en Venezuela hacia el socialismo del siglo XXI. Caracas: Monte Ávila Editores, 2009.

WOOD, Ellen Meiksins. Democracia contra capitalismo: a renovação do materialismo histórico. São Paulo: Boitempo, 2011.

\section{GANPHLAC}

Revista Eletrônica da ANPHLAC, ISSN 1679-1061, №. 21, p. 149-175, Jul./Dez., 2016.

http://revista.anphlac.org.br 
ZELIK, Raúl. ¿"Socialismo del siglo XXI” o viejo centralismo estatal? Una lectura disidente de las transformaciones en Venezuela. Fórum: Revista del Departamiento de Ciencia Política, n. 1. Mendelin: Universidad Nacional, 2011, p. 13-34. 